\title{
Magnetic Stimulation of the Right Visual Cortex Impairs Form-specific Priming
}

\author{
Gorana Pobric $^{1}$, Stefan R. Schweinberger ${ }^{2}$, and Michal Lavidor ${ }^{1}$
}

\begin{abstract}
Recent evidence suggests that priming of objects across different images (abstract priming) and priming of specific images of an object (form-specific priming) are mediated by dissociable neural processing subsystems that operate in parallel and are predominantly linked to left and right hemispheric processing, respectively [Marsolek, C. J. Dissociable neural subsystems underlie abstract and specific object recognition. Psychological Science, 10, 111-118, 1999]. Previous brain imaging studies have provided important information about the neuroanatomical regions that are involved in form-specific and abstract priming; however, these techniques did not fully establish the functional significance of priming-related changes in cortical brain activity. Here, we used repetitive transcranial magnetic stimulation (rTMS) in order to establish the functional role of the right oc-
\end{abstract}

\section{INTRODUCTION}

Priming is a nonconscious form of memory that involves a change in a person's ability to identify, produce, or classify an item due to a previous encounter with that or a related item (Schacter, Dobbins, \& Schnyer, 2004). For example, priming in the lexical decision task is observed when participants are faster and more accurate in categorizing letter strings as words when these words were studied in an earlier episode (Bowers, 1996). One type of visual priming is form-specific priming, where facilitation results from visual similarity or identity between prime and target. Together with abstract visual form priming, these two systems are fundamental to visual recognition, as we need both the ability to recognize the abstract category to which an input shape corresponds (e.g., keyboard vs. pen), as well as the ability to recognize a specific image or exemplar to which that same input shape corresponds (e.g., a specific pen). For words, the abstract format of orthographic knowledge is the ability to map perceptually dissimilar words (READ/read) onto a common abstract orthographic representation (Bowers, Vigliocco, \& Haan, 1998). Com-

\footnotetext{
${ }^{1}$ University of Hull, United Kingdom, ${ }^{2}$ Friedrich-Schiller-University, Germany
}

cipital cortex in form-specific priming [Kroll, N. E. A., Yonelinas, A. P., Kishiyama, M. M., Baynes, K., Knight, R. T., \& Gazzaniga, M. S. The neural substrates of visual implicit memory: Do the two hemispheres play different roles? Journal of Cognitive Neuroscience, 15, 833-842, 2003]. Compared to no TMS and sham TMS, rTMS of the right occipital cortex disrupted immediate form-specific priming in a semantic categorization task. Left occipital rTMS, on the other hand, had no converse effect on abstractive priming. Abstract priming may involve deeper semantic processing and may be unresponsive to magnetic stimulation of a single cortical locus. Our TMS results show that form-specific priming relies on a visual word-form system localized in the right occipital lobe, in line with the predictions from divided visual field behavioral studies [Marsolek, 1999]. plementary to this is that the form-specific subsystem enables the identification of specific letter cases, fonts, and scripts. There is disagreement over the neuroanatomical substrates of this form of priming that we aimed to resolve here by using magnetic stimulation.

Recent evidence suggests that priming of objects across different images and priming of specific images of an object occur in dissociable neural processing subsystems that operate in parallel (Marsolek, 1999). Marsolek, Kosslyn, and Squire (1992) first reported that casespecific visual priming for words is greater when test stimuli are presented initially in the right cerebral hemisphere (RH). In contrast, case-specific explicit memory for words is not greater when stimuli are presented initially in the left hemisphere (LH). Marsolek and colleagues (Marsolek, 1995, 1999, 2004; Burgund \& Marsolek, 1997; Marsolek et al., 1992) suggested that an abstract representations subsystem operates more effectively than the specific representations subsystem in the LH, and the specific subsystem operates more effectively than the abstract subsystem in the RH.

Although the work of Marsolek (1999, 2004) and Burgund and Marsolek (1997) continued to support the lateralization of abstract and form-specific systems, others have reported completely different patterns. Koivisto (1996), for example, showed that for uppercase 
targets, there was evidence for form-specific priming that was exclusive to the RH. However, lowercase test items did not reveal any hemispheric asymmetries in form-dependent priming, indicating that in some conditions form-specific representations are computed in the LH as well. Kroll et al. (2003) have shown that the $\mathrm{RH}$ is involved in form-specific priming, but only when using a specific memory test (stem completion). Kroll, Rocha, Yonelinas, Baynes, and Frederick (2001) reported that in the fragment-completion task both hemispheres were capable of supporting form-specific visual implicit memory. In addition, Koivisto did not find any asymmetries in the abstract component of priming, in line with more recent findings (Bowers \& Turner, 2005).

Patient data gave more consistent support of the lateralized abstract/specific duality. A case study reported by Samuelsson, Bogges, and Karlsson (2000) suggested that the RH is necessary for normal visual priming. More specifically, Vaidya, Gabrieli, Verfaellie, Fleischman, and Askari (1998) have examined visual priming in patients with global amnesia and patient M.S., who had a right occipital lobectomy. Word stems appeared in the same or different font as study words. Amnesic patients showed normal font-specific priming despite impaired word-stem cued recall; however, patient M.S. failed to exhibit font-specific priming despite preserved declarative memory. Therefore, Vaidya et al. concluded that perceptual specificity in visual priming depends on visual processes mediated by the right occipital lobe rather than medial temporal and diencephalic regions involved in declarative memory. In accordance, Kroll et al. (2003) have shown that the right occipital cortex is involved in form-specific priming, but only when using a specific memory test (stem completion). However, Yonelinas et al. (2001) argued that the right occipital lobe does not play a necessary role in visual implicit memory, and that the isolated LH can support normal levels of visual priming in a variety of tasks. In addition, a different priming region in the $\mathrm{RH}$, the right extrastriate cortex, was suggested as the locus for same-format specific system (functional magnetic resonance imaging [fMRI]: Dehaene et al., 2001; positron emission tomography: Lebreton, Desgranges, Landeau, Baron, \& Eustache, 2001).

In light of the disagreement over the neuroanatomical substrates of this form of priming, we sought to examine the extent of the $\mathrm{RH}$ involvement in formspecific priming. We assessed the performance of the two hemispheres in a masked priming task when visual function was disrupted with transcranial magnetic stimulation (TMS) of the left and right occipital areas. The basis for this study has its precedence in previous work that has used TMS to suppress visual processing. Performance on several different types of visual recognition tasks has been shown to be impaired with magnetic stimulation of the occipital cortex (e.g., Skarratt \& Lavidor, 2006; Campana, Cowey, \& Walsh,
2002; Cowey \& Walsh, 2000; Kammer, 1999; Kastner, Demmer, \& Ziemann, 1998; Amassian et al., 1989, 1993, 1998). Furthermore, we recently showed that processing left visual field (LVF) targets was significantly impaired with repetitive TMS (rTMS) to the right occipital cortex, whereas no significant impairment was observed for right visual field (RVF) target processing. The complementary pattern of rTMS effects was obtained with LH stimulation, which significantly impaired lexical decision performance to RVF but not LVF targets (Lavidor, Ellison, \& Walsh, 2003).

The use of TMS therefore allowed us to investigate lexical processing in the $\mathrm{RH}$ and $\mathrm{LH}$ under conditions of TMS-induced impairment of the left and right occipital areas. We assessed the ability of participants to conduct semantic categorization of animal and professions words that were primed by identical words, by the same words that differed in letter case, or by unrelated words. rTMS was applied to the $\mathrm{LH}$ and $\mathrm{RH}$ occipital areas as participants made semantic categorization responses to words that represented animals or professions. All the target words were presented in lower case and were primed by the same or unrelated words (repetition priming), where half of the same primes were in lower case (formspecific priming), and half were in upper case (abstract priming). We expected to observe form-specific priming and abstract priming in the control conditions. Crucially, we expected rTMS of the right occipital region to impair form-specific priming. Lack of such impairment would imply that either the right occipital cortex is not involved in form-specific priming (in line with Dehaene et al., 2001), or that both hemispheres can benefit from samecase repetition priming (in accordance with Bowers \& Turner, 2005). In addition, if rTMS over the left occipital cortex would yield selective effects for targets preceded with uppercase primes, that might support the complementary hypothesis of Marsolek (1999), that is, the existence of an abstract priming mechanism that is lateralized to the LH. We should note that this prediction is less likely, as the identification of abstract letter identities (i.e., the mapping from $\mathrm{A} \rightarrow$ a) relies heavily on memory processes and differs from perceptual priming (see e.g., Schott, Richardson-Klavehn, Heinze, \& Düzel, 2002). Whereas left frontal neural correlates were suggested as the locus for nonperceptual priming (Wig, Grafton, Demos, \& Kelley, 2005), the left occipital cortex was never linked to such processes, so there was no reason to expect selective involvement of the left visual cortex in abstract priming.

\section{METHODS}

\section{Design}

A $4 \times 2 \times 2$ within-subjects design was used, with TMS (no stimulation, RH stimulation, LH stimulation, or sham), prime type (repetition, unrelated), and prime 
letter case (upper, lower) as the three factors. rTMS was administered in alternating blocks of single-hemisphere stimulation. All other variables were randomly applied. Sham rTMS trials were included to assess the potential effects that the auditory and tactile stimulation from the coil might have on performance. During these trials, the lateral edge of the coil was held perpendicular to the scalp, using the same left and right occipital sites used for actual rTMS stimulation. This form of sham stimulation does not produce measurable evoked potentials or right cerebral blood flow changes when applied over the motor cortex (Loo et al., 2000; George et al., 1997).

\section{Participants}

Twelve right-handed volunteers participated in the experiment $(7$ women; mean age $=24.8$ years, $S D=4.1$; mean Edinburgh Handedness Inventory score $=82.3$, $S D=10.1)$ (Oldfield, 1971). All reported normal or corrected-to-normal vision and were naive to the purposes of the experiment. The experiments were undertaken with the understanding and written consent of each participant. Local ethical committee approval was granted for all procedures in accordance with the Code of Ethics of the World Medical Association (Declaration of Helsinki).

\section{Stimuli and Apparatus}

Visual stimuli were presented on a Pentium PC linked to a $100-\mathrm{Hz}$ color monitor. Stimuli were 80 words, 40 from the animal category and 40 from the professions category. All stimuli were 8-12 characters long, and words from the two categories were matched for word length, frequency, concreteness, and part of speech (norms were taken from the English Project Lexicon; Balota et al., 2002). The target words were always presented in the lower case. The 80 target words were divided into two matched lists, List A and List B, each containing 20 animal words and 20 profession words, that were used to counterbalance the priming conditions in a Latin square design.

Prime words were presented either in the lower or in the upper case. The combined presentation of prime and target words created four prime types:

1. Form-specific priming, where prime and target were identical and were both in lower case ("alligator" for the target "alligator").

2. Abstract priming, where prime and target were identical but differed in letter case because primes were presented in upper case ("ALLIGATOR" for the target "alligator").

3. Unrelated primes in lower case ("alligator" for the target "assistant").
4. Unrelated primes in upper case ("ALLIGATOR" for the target "assistant").

The two lists of target words (List A and List B) were rotated across the priming conditions such that each word had an equal chance of appearing in each condition. Each TMS condition was repeated for a total of 160 trials, administered in four blocks of 40 trials. During the experiment, each combination of the within-subjects factors repeated 40 times, with 20 animal target words and 20 profession words; hence, each subject was exposed to a total of 640 experimental trials (administered in 16 blocks of 40 trials each). Twenty-four practice trials preceded the 640 experimental trials. Participants were instructed to take a break between blocks and to continue when they were ready.

\section{TMS Equipment}

A MagStim Super Rapid stimulator with four external boosters was used (maximum output, approximately $2 \mathrm{~T}$ ). Magnetic stimulation was applied using a $70-\mathrm{mm}$ figure-of-eight coil. The double-wire windings that make up the figure-of-eight coil carry two alternating electrical currents that converge at the point where the two coils meet (at the center of the figure-of-eight). A focal electrical current can then be induced in the cortex via magnetic conduction from this central point, which undergoes minimal attenuation by the intervening soft tissue and bone. Previous studies have demonstrated that magnetic stimulation using this type of coil can produce functionally dissociable effects when moving the coil by $5-10 \mathrm{~mm}$ across the scalp (BrasilNeto, McShane, Fuhr, Hallett, \& Cohen, 1992). The center of the coil was positioned over the site to be stimulated such that the windings were to the left and to the right of it and the handle of the coil pointed vertically.

\section{Procedure}

\section{Preexperiment: Induction of Stationary Phosphenes}

Before attempting to disrupt word processing with rTMS, the occipital stimulation sites were established by eliciting phosphenes to ensure that hemispheric stimulation selectively affected contralateral visual field processing. Participants wore a latex swimming cap and were seated with their head supported by a chin rest and head strap to secure head position and stabilize fixation. The upper edge of the inion was marked on the cap, and another point (the reference point) was marked $2 \mathrm{~cm}$ above it. The occipital sites that were marked on the cap were $2 \mathrm{~cm}$ to the left (the $\mathrm{LH}$ site) of the reference point and $2 \mathrm{~cm}$ to the right (the RH site). The coordinates were selected initially on the basis of previously successful studies with TMS, in 
which stationary phosphenes and the suppression of visual perception tasks with TMS were reported at similar sites (Lavidor et al., 2003; Pascual-Leone \& Walsh, 2001; Stewart, Ellison, Walsh, \& Cowey, 2001; Cowey \& Walsh, 2000; Kammer, 1999; Stewart, Battelli, Walsh, \& Cowey, 1999; Kastner et al., 1998; Amassian et al., 1989).

During this preexperiment phase, we located the stimulation sites with single pulses of TMS delivered between $60 \%$ and $90 \%$ of stimulator output. In a darkened room, participants closed their eyes while TMS was delivered to the LH and RH points. TMS was applied at increasing intensities until participants reliably reported seeing phosphenes and could describe their position in space. For some participants, the magnetic stimulation sites were changed using the "hunting procedure" described by Ashbridge, Walsh, and Cowey (1997). Once a site yielded reliable phosphene reports, an additional preexperimental phase was conducted to further verify the site. This involved using TMS to induce artificial scotomas (as reported by Kamitani \& Shimojo, 1999). We found that participants who reported phosphenes also reported this type of scotoma.

\section{Main Experiment}

One rTMS train was delivered per trial at the onset of the visual target word and was triggered remotely by the same PC that generated visual stimuli. For the main experiment, we used the effective phosphene sites for each participant with the stimulator output fixed at $64 \%$ of maximum, at $10 \mathrm{~Hz}$ for $500 \mathrm{msec}$. This intensity was selected on the basis of previous experiments and has been found to sufficiently disrupt perception without masking stimuli with overt phosphenes (Lavidor et al., 2003; Lavidor \& Walsh, 2003).

Trials were blocked as a function of TMS condition to allow for subject rest periods and coil heating. There were 16 blocks in total, each comprising 40 trials. There were four blocks for each TMS condition, comprising a total of 160 trials per TMS condition. The 4 sham TMS blocks included 2 blocks of sham TMS over LH and 2 blocks of sham TMS over RH.

The sequence of events on trials was as follows: a fixation cross that lasted for $500 \mathrm{msec}$, forward mask for $15 \mathrm{msec}$, followed by a prime word (upper and lower case) for $45 \mathrm{msec}$, target word for $200 \mathrm{msec}$ at screen center, backward mask for $15 \mathrm{msec}$, and blank screen until response. rTMS (or sham rTMS) was administered at the point of target word onset. Participants gave 2 alternative forced-choice (2-AFC) semantic categorization responses (is it a profession or an animal?) by pressing one of two available keys on a standard keyboard and were instructed to respond as quickly and as accurately as possible. Response keys were reversed for half of the participants. Participants were given a single block of 24 practice trials before the start of the experiment.

\section{RESULTS}

Response times (RTs) that were shorter than 300 msec or longer than 1300 msec were discarded either as anticipatory or excessively lengthy, respectively. This resulted in the removal of approximately $1.8 \%$ of all responses. Data from the different sham TMS blocks were combined. Table 1 summarizes the mean RTs and error rates.

In a repeated measures analysis, TMS condition (no TMS, sham TMS, TMS over left occipital and TMS over right occipital), priming (repletion or unrelated), and prime letter case (upper or lower) as the within-subjects factors were analyzed to examine their effects on latencies of semantic categorization. Note that letter case is the operational definition of priming type, where lowercase primes provide the form-specific priming (for repetition primes), and uppercase primes provide the abstract primes (for related primes) for the target words, which were always presented in lower case.

There was a significant priming effect, $F(1,11)=89.5$, $p<.0001$, with words preceded by related primes (mean $\mathrm{RT}=659 \mathrm{msec}$ ) responded to faster then when unrelated primes precede the targets (mean $=728 \mathrm{msec}$ ). Prime

Table 1. Mean Reaction Times (and Standard Deviations) (in Milliseconds) to Target Words and Error Scores as a Function of Prime Type, Prime Letter Case, and Site of rTMS

\begin{tabular}{|c|c|c|c|c|}
\hline & $\begin{array}{l}\text { Uppercase } \\
\text { Related } \\
\text { Primes }\end{array}$ & $\begin{array}{c}\text { Uppercase } \\
\text { Unrelated } \\
\text { Primes }\end{array}$ & $\begin{array}{c}\text { Lowercase } \\
\text { Repetition } \\
\text { Primes }\end{array}$ & $\begin{array}{c}\text { Lowercase } \\
\text { Unrelated } \\
\text { Primes }\end{array}$ \\
\hline \multicolumn{5}{|l|}{ No TMS } \\
\hline Mean RT & 666 & 721 & 616 & 709 \\
\hline$S D$ & 105 & 87 & 93 & 78 \\
\hline \% Error & 5.1 & 5.7 & 7.1 & 9.3 \\
\hline \multicolumn{5}{|c|}{ TMS_left occipital } \\
\hline Mean RT & 674 & 738 & 636 & 724 \\
\hline$S D$ & 107 & 96 & 78 & 99 \\
\hline \% Error & 5.6 & 7.8 & 4.2 & 7.4 \\
\hline \multicolumn{5}{|c|}{ TMS_right occipital } \\
\hline Mean RT & 668 & 741 & 690 & 715 \\
\hline$S D$ & 98 & 99 & 86 & 85 \\
\hline \% Error & 5.9 & 6.5 & 6.5 & 6.6 \\
\hline \multicolumn{5}{|l|}{ Sham TMS } \\
\hline Mean RT & 682 & 734 & 639 & 727 \\
\hline$S D$ & 107 & 89 & 126 & 102 \\
\hline \% Error & 3.8 & 4.8 & 5.6 & 7.9 \\
\hline
\end{tabular}

Targets were always presented in lower case. 
letter case also had a significant effect on RTs, $F(1,11)=$ $31.1, p<.001$, with lowercase primes yielding faster response (683 msec) than uppercase primes (704 msec).

There was a significant interaction between the TMS condition, prime type, and prime letter case for RT, $F(3,33)=7.78, p<.01$. Separate simple-effects analyses were carried out to test the priming effects across the two letter case conditions. For lowercase primes (that generate form-specific priming), there was a significant interaction of TMS condition and prime type, $F(3,33)=$ $11.58, p<.001$, whereas for uppercase primes (i.e., abstract priming), the interaction of TMS condition and prime type did not reach significance, $F(3,33)=1.26$, $p=.3$. Further post hoc Bonferroni comparisons $(p<$ $.05)$ yielded that the slower RT for repetition primes when rTMS was applied over the right occipital cortex significantly differed from the other TMS conditions. These results clearly show that form-specific priming effects were consistently evident in all the control conditions, except when rTMS was applied over the right visual cortex. Abstract priming (with uppercase related primes) on the other hand, was not affected by the TMS application. In order to illustrate this interaction, we plotted the priming effects (i.e., the mean RT difference between unrelated and related primes) as a function of prime type (form-specific with lowercase repetition primes or abstract with uppercase related primes) and TMS condition (Figure 1). As noted in Figure 1, no TMS, sham TMS, and LH magnetic stimulation allowed formspecific priming, that is, the faster responses to samecase primes and targets. However, rTMS over the RH

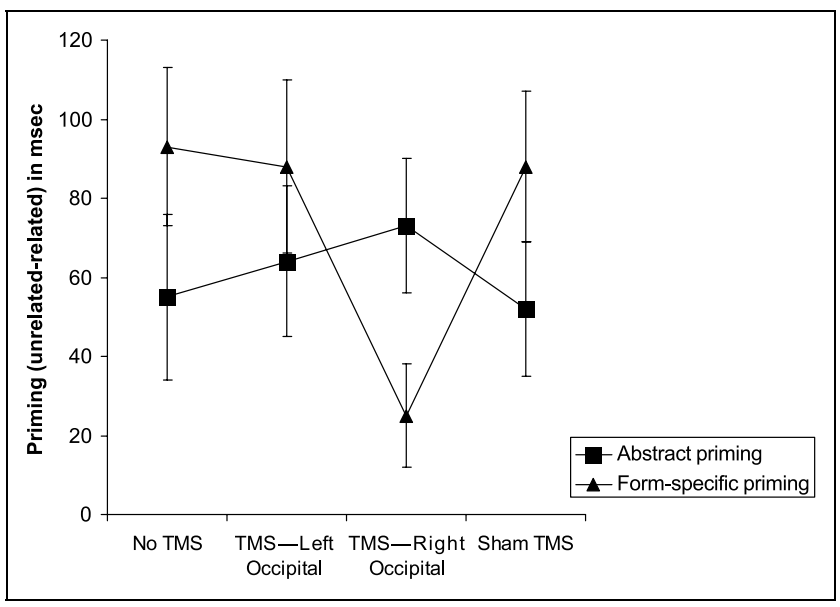

Figure 1. Mean priming size (and standard deviation) for response times for lowercase target words as a function of prime type and rTMS stimulation site. The lines represent the difference in milliseconds between unrelated and repetition primes, calculated separately for uppercase primes (abstract priming) and lowercase primes (form-specific priming). Under control conditions (i.e., no TMS, sham TMS, and left occipital stimulation) there was a significant form-specific priming that was abolished following rTMS over the right occipital cortex. In contrast, abstract priming was not affected by magnetic stimulation. prevented the form-specific priming. Abstract priming was evident in all rTMS conditions.

When focusing on repetition priming only, we can calculate a different measure of form-specific priming by looking at the difference between same (lower case) and different letter case (upper case) primed items (see Table 1). Post hoc Bonferroni comparisons $(p<$ $.05)$ revealed that under no TMS, sham TMS, and LH magnetic stimulation, same-case repetition priming was significantly bigger then related uppercase priming. However, under rTMS over the RH, the form-specific priming did not differ from uppercase related priming. Indeed, RTs following same-case related primes (690 msec) were actually slower than following different-case related primes in this condition (mean RT $=668 \mathrm{msec}$ ); however, this difference was not significant. This (nonsignificant) inhibition is unexpected: If the right occipital TMS had selectively abolished form-specific primes, we would have expected the priming benefit here to be similar to that found for abstract priming. We cannot explain this unexpected effect, and future experimentation is required to establish its robustness and explore its cause.

Accuracy was high at all conditions (above 92\%). There were no main effects or interactions for the accuracy measure, probably due to ceiling effects (see Table 1 for accuracy means).

\section{DISCUSSION}

The primary aim of our study was to examine the extent of the $\mathrm{RH}$ involvement in form-specific priming. We assessed the performance of the two hemispheres in a masked repetition priming task when visual functioning was disrupted with TMS of the left and right occipital areas. Target words in lower case were presented with uppercase primes (abstract priming), lowercase primes (form-specific priming), or unrelated primes. When rTMS was applied to the right occipital cortex, we observed immediate disruption of form-specific priming during semantic categorization task. Abstract priming (with upper case primes), on the other hand, was not affected by the TMS application.

These findings provide direct evidence that formspecific priming is lateralized to the $\mathrm{RH}$. Numerous studies report instances of neuronal (Kroll et al., 2001, 2003; Yonelinas et al., 2001; Vaidya et al., 1998; Burgund \& Marsolek, 1997; Marsolek et al., 1992) and hemodynamic reductions (Schacter et al., 2004; Dehaene et al., 2001; Lebreton et al., 2001; Schacter, Badgaiyan, \& Alpert, 1999) in implicit memory regarding form-specific and abstract priming. Evidence for a specific involvement of the RH in form-specific priming has also been found by Koutstaal et al. (2001) and by Schweinberger, Pickering, Burton, and Kaufmann (2002). However, the correlative nature of the above-mentioned studies until now could not establish a direct link between $\mathrm{RH}$ and 
form-specific priming. In contrast, our results are consistent with the theory that form-specific priming relies on a visual word-form system localized in the right occipital lobe, in line with the predictions from divided visual field behavioral studies (Marsolek, 1999). That is, we showed that a normal functioning of the right visual cortex is necessary to benefit from repeated exposure of words. Our data cannot tell whether the right visual cortex is also sufficient for the form-specific priming, as potentially additional $\mathrm{RH}$ regions might be involved in the form-specific priming. However, based on previous lesion studies, the right occipital cortex was the most likely candidate for testing TMS effects on form-specific priming (see Kroll et al., 2003).

In contrast to the selective disruption effects we generated to form-specific priming, the abstract priming (i.e., when primes and targets differed in letter case) was not affected by the magnetic stimulation. The most likely account is that the mapping between the representations of upper- and lowercase letters requires deeper processing than the visual processing taking place in the primary visual cortex; therefore, TMS over such areas did not interfere with the abstract priming. A possible LH region that computes the abstract letter identities is the left fusiform gyrus (FFG), as suggested by Cohen et al. (2003). Theoretically, TMS over that area might generate selective disruption to abstract priming, thus giving further support to Marsolek's theory (1999, 2004); unfortunately, current TMS coils cannot reliably access the left FFG.

Lack of impairment in the left occipital cortex implies that both hemispheres are not equally involved in samecase repetition priming as previously argued by Bowers and Turner (2005). However, we cannot rule out the contribution that other nonvisual areas, such as the right parietal cortex, that receive visual input from V1, might make to word form processing. Further studies might focus on connectivity issues (Paus et al., 1997), and look for additional regions of interest in the RH that might contribute to form priming, where TMS with its various protocols is a very suitable research method.

The rTMS effects we found for briefly presented targets are consistent with other rTMS findings with occipital stimulation in which TMS is only able to disrupt perceptual judgments if the relative duration of presentation is short (e.g., Amassian et al., 1989), stimuli are close to luminance detection thresholds (Miller, Fendrich, Eliassen, Demirel, \& Gazzaniga, 1996), or both (see Kammer \& Nusseck, 1998; see also Walsh \& Cowey, 2000; Walsh \& Pascual-Leone, 2003, for details of the relationship between stimuli and the temporal duration of TMS effects). In the present study, we did not find significant TMS effects on error rates. Although errors may be a useful measure of performance close to threshold, it has been difficult to obtain errors in cognitive tasks with TMS (see Walsh \& Pascual-Leone, 2003; Walsh \& Cowey, 1998, for methodological details).
Our finding is in partial support of a two-system hypothesis proposed by Marsolek and colleagues (Marsolek, 1995, 1999, 2004; Burgund \& Marsolek, 1997; Marsolek et al., 1992). According to the two-system hypothesis, form-specific priming depends on a subsystem in the $\mathrm{RH}$, whereas priming that generalizes across letter case depends on a subsystem in the LH. By reducing priming effect for identical prime-target pairs with rTMS applied to the right occipital cortex, we have shown that visual word identification is lateralized. However, we did not find support to the complementary assumption that assumes the existence of abstract priming mechanism in the LH, at least not when TMS was applied over the left visual cortex. The possibility that other different $\mathrm{LH}$ areas are involved in abstract priming cannot be ruled out by our results (for candidate LH region see Cohen et al., 2003).

Moreover the findings of our study are consistent with several patient studies (Kroll et al., 2003; Vaidya et al., 1998). Whereas Kroll et al. (2003) have shown that the $\mathrm{RH}$ is involved in form-specific priming only when using a specific memory test (stem completion), by using a virtual lesion technique, we have extended this finding to a different task (semantic categorization). In an fMRI study (Dehaene et al., 2001) when prime and targets were presented in the same case, there was a priming-related activity reduction in two regions of the right extrastriate occipital cortex. No such reduction was observed when the prime-target pairs were presented in different cases. Conversely, in the left occipital cortex, there were similar priming-related reductions in activity for both the same and different case conditions. Similarly to Dehaene et al. (2001), we observed right lateralization for the form-specific priming. However, whereas their finding was related to extrastriate areas, we found reduction of form-specific priming effect in the right V1. It would therefore be interesting to see if these results could be extended to the extrastriate cortex as well. We did not observe significant reduction in priming either for the same case or for different case when rTMS was applied to the left occipital cortex.

In conclusion, we present sound evidence that specific form priming is localized in the RH. Still, significant priming effects are observed even when the prime-target format is changed. This indicates that implicit memory tasks can rely on abstract-form memory processes as well. It is plausible that abstract priming involves deeper semantic processing and therefore cannot be affected by magnetic stimulation of a single cortical locus.

\section{Acknowledgments}

This study was supported by a European Commission funded research and training network (RTN:LAB, MRTN-CT-2004-512141) entitled Language and Brain. 
Reprint requests should be sent to Michal Lavidor, Department of Psychology, University of Hull, Cottingham Road, Hull HU6 7RX, United Kingdom, or via e-mail: m.lavidor@hull.ac.uk.

\section{REFERENCES}

Amassian, V. E., Cracco, R. Q., Maccabee, P. J., Cracco, J. B., Rudell, A. P., \& Eberle, L. (1989). Suppression of visual perception by magnetic coil stimulation of human occipital cortex. Electroencephalography and Clinical Neurophysiology, 74, 458-462.

Amassian, V. E., Cracco, R. Q., Maccabee, P. J., Cracco, J. B., Rudell, A. P., \& Eberle, L. (1993). Unmasking human visual-perception with the magnetic coil and its relationship to hemispheric asymmetry. Brain Research, 605, 312-316.

Amassian, V. E., Cracco, R. Q., Maccabee, P. J., Cracco, J. B., Rudell, A. P., \& Eberle, L. (1998). Transcranial magnetic stimulation in the study of the visual pathway. Journal of Clinical Neurophysiology, 15, 288-304.

Ashbridge, E., Walsh, V., \& Cowey, A. (1997). Temporal aspects of visual search studied by transcranial magnetic stimulation. Neuropsychologia, 35, 1121-1131.

Balota, D. A., Cortese, M. J., Hutchison, K. A., Neely, J. H., Nelson, D., Simpson, G. B., et al. (2002). The English Lexicon Project: A web-based repository of descriptive and behavioral measures for 40,481 English words and nonwords. Retrieved from elexicon.wustl.edu/.

Bowers, J. S. (1996). Different perceptual codes support priming for words and pseudowords: Was Morton right all along? Journal of Experimental Psychology: Learning, Memory, and Cognition, 22, 1336-1353.

Bowers, J. S., \& Turner, E. L. (2005). Masked priming is abstract in the left and right visual fields. Brain and Language, 95, 414-422.

Bowers, J. S., Vigliocco, G., \& Haan, R. (1998). Orthographic, phonological, and articulatory contributions to masked letter and word priming. Journal of Experimental Psychology: Human Perception and Performance, 24, 1705-1719.

Brasil-Neto, J. P., McShane, L. M., Fuhr, P., Hallett, M., \& Cohen, L. G. (1992). Topographic mapping of the human motor cortex with magnetic stimulation: Factors affecting accuracy and reproducibility. Electroencephalography and Clinical Neurophysiology, 85, 9-16.

Burgund, E. D., \& Marsolek, C. J. (1997). Letter-case specific priming in the right cerebral hemisphere with a form-specific perceptual identification task. Brain and Cognition, 35, 239-258.

Campana, G., Cowey, A., \& Walsh, V. (2002). Priming of motion direction and area V5/MT: A test of perceptual memory. Cerebral Cortex, 12, 663-669.

Cohen, L., Martinaud, O., Lemer, C., Lehericy, S., Samson, Y., Obadia, M., et al. (2003). Visual word recognition in the left and right hemispheres: Anatomical and functional correlates of peripheral alexias. Cerebral Cortex, 13, $1313-1333$

Cowey, A., \& Walsh, V. (2000). Magnetically induced phosphenes in sighted, blind and blindsighted observers. NeuroReport, 11, 3269-3273.

Dehaene, S., Naccache, L., Cohen, L., Le Bihan, D., Mangin, J. F., Poline, J. B., et al. (2001). Cerebral mechanisms of word masking and unconscious repetition priming. Nature Neuroscience, 4, 752-758.

George, M. S., Wasserman, E. M., Kimbrell, T. A., Little, J. T., Williams, W. E., Danielson, A. L., et al. (1997). Mood improvement following daily left prefrontal repetitive transcranial magnetic stimulation in patients with depression: A placebo-controlled crossover trial. American Journal of Psychiatry, 154, 1752-1756.

Kamitani, Y., \& Shimojo, S. (1999). Manifestation of scotomas created by transcranial magnetic stimulation of human visual cortex. Nature Neuroscience, 2, 767-771.

Kammer, T. (1999). Phosphenes and transient scotomas induced by magnetic stimulation of the occipital lobe: Their topographic relationship. Neuropsychologia, 36, 191-198.

Kammer, T., \& Nusseck, H. G. (1998). Are recognition deficits following occipital lobe TMS explained by raised detection thresholds? Neuropsychologia, 36, 1161-1166.

Kastner, S., Demmer, I., \& Ziemann, U. (1998). Transient visual field defects induced by transcranial magnetic stimulation over human occipital pole. Experimental Brain Research, 118, 19-26.

Koivisto, M. (1996). Form-specific priming and functional brain asymmetries in perceptual identification. Cortex, 32, 527-536.

Koutstaal, W., Wagner, A. D., Rotte, M., Maril, A., Buckner, R. L., \& Schacter, D. L. (2001). Perceptual specificity in visual object priming: Functional magnetic resonance imaging evidence for a laterality difference in fusiform cortex. Neuropsychologia, 39, 184-199.

Kroll, N. E. A., Rocha, D. A., Yonelinas, A. P., Baynes, K., \& Frederick, C. (2001). Form-specific visual priming in the left and right hemispheres. Brain and Cognition, 47, 564-569.

Kroll, N. E. A., Yonelinas, A. P., Kishiyama, M. M., Baynes, K., Knight, R. T., \& Gazzaniga, M. S. (2003). The neural substrates of visual implicit memory: Do the two hemispheres play different roles? Journal of Cognitive Neuroscience, 15, 833-842.

Lavidor, M., Ellison, A., \& Walsh, V. (2003). Examination of a split-processing model of visual word recognition: A magnetic stimulation study. Visual Cognition, 10, 341-362.

Lavidor, M., \& Walsh, V. (2003). A magnetic stimulation examination of orthographic neighborhood effects in visual word recognition. Journal of Cognitive Neuroscience, 15, 354-363.

Lebreton, K., Desgranges, B., Landeau, B., Baron, J. C., \& Eustache, F. (2001). Visual priming within and across symbolic format using a tachistoscopic picture identification task: A PET study. Journal of Cognitive Neuroscience, 13, 670-686.

Loo, C. K., Taylor, J. L., Gandevia, S. C., McDarmont, B. N., Mitchell, P. B., \& Sachdev, P. S. (2000). Transcranial magnetic stimulation (TMS) in controlled treatment studies: Are some "sham" forms active? Biological Psychiatry, 47, 325-331.

Marsolek, C. J. (1995). Abstract visual-form representations in the left cerebral hemisphere. Journal of Experimental Psychology: Human Perception and Performance, 21, 375-386.

Marsolek, C. J. (1999). Dissociable neural subsystems underlie abstract and specific object recognition. Psychological Science, 10, 111-118.

Marsolek, C. J. (2004). Abstractionist versus exemplar-based theories of visual word priming: A subsystems resolution. The Quarterly Journal of Experimental Psychology, 57, 1233-1259.

Marsolek, C. J., Kosslyn, S. M., \& Squire, L. R. (1992). Form-specific visual priming in the right cerebral hemisphere. Journal of Experimental Psychology. Learning, Memory, and Cognition, 18, 492-508.

Miller, M. B., Fendrich, R., Eliassen, J. C., Demirel, S., \& Gazzaniga, M. S. (1996). Transcranial magnetic 
stimulation: Delays in visual suppression due to luminance changes. NeuroReport, 7, 1740-1744.

Oldfield, D. P. (1971). The assessment and analyses of handedness. The Edinburgh inventory. Neuropsychologia, 9, 97-113.

Pascual-Leone, A., \& Walsh, V. (2001). Fast back projections from the motion to the primary visual area necessary for visual awareness. Science, 292, 510-512.

Paus, T., Jech, R., Thompson, C. J., Comeau, R., Peters, T., \& Evans, A. C. (1997). Transcranial magnetic stimulation during positron emission tomography: A new method for studying connectivity of the human cerebral cortex. Journal of Neuroscience, 17, 3178-3184.

Samuelsson, S., Bogges, T. R., \& Karlsson, T. (2000). Visual implicit memory deficit and developmental surface dyslexia: A case of early occipital damage. Cortex, 36, 365-376.

Schacter, D. L., Badgaiyan, R. D., \& Alpert, N. M. (1999). Visual word stem completion priming within and across modalities: A PET study. NeuroReport, 10, 2061-2065.

Schacter, D. L., Dobbins, I. G., \& Schnyer, D. M. (2004). Specificity of priming: A cognitive neuroscience perspective. Nature Reviews Neuroscience, 5, 853-862.

Schott, B., Richardson-Klavehn, A., Heinze, H. J., \& Düzel, E. (2002). Perceptual priming versus explicit memory: Dissociable neural correlates at encoding. Journal of Cognitive Neuroscience, 14, 578-592.

Schweinberger, S. R., Pickering, E. C., Burton, A. M., \& Kaufmann, J. M. (2002). Human brain potential correlates of repetition priming in the recognition of faces and names. Neuropsychologia, 40, 2057-2073.
Skarratt, P. A., \& Lavidor, M. (2006). Magnetic stimulation of the left visual cortex impairs expert word recognition. Journal of Cognitive Neuroscience, 18, 1749-1758.

Stewart, L., Battelli, L., Walsh, V., \& Cowey, A. (1999). Motion perception and perceptual learning: A magnetic stimulation study. Electroencephalography and Clinical Neurophysiology, 51, 334-350.

Stewart, L., Ellison, A., Walsh, V., \& Cowey, A. (2001). Transcranial magnetic stimulation in studies of vision, attention and language. Acta Psychologica, 107, 275-291.

Vaidya, C. J., Gabrieli, J. D. E., Verfaellie, M., Fleischman, D., \& Askari, N. (1998). Font-specific priming following global amnesia and occipital lobe damage. Neuropsychology, 12, 183-192.

Walsh, V., \& Cowey, A. (1998). Magnetic stimulation studies of visual cognition. Trends in Cognitive Sciences, 2, 103-110.

Walsh, V., \& Cowey, A. (2000). Transcranial magnetic stimulation and cognitive neuroscience. Nature Reviews Neuroscience, 1, 73-79.

Walsh, V., \& Pascual-Leone, A. (2003). Transcranial magnetic stimulation: A neurochronometrics of mind. Cambridge: MIT Press.

Wig, G. S., Grafton, S. T., Demos, K. E., \& Kelley, W. M. (2005). Reductions in neural activity underlie behavioral components of repetition priming. Nature Neuroscience, $8,1228-1233$.

Yonelinas, A. P., Kroll, N. E. A., Baynes, K., Dobbins, I. G., Frederick, C. M., Knight, R. T., et al. (2001). Visual implicit memory in the left hemisphere: Evidence from patients with callosotomies and right occipital lobe lesions. Psychological Science, 12, 293-298. 